\title{
Theoretical Study of Optical and Electrical Properties of Organic Photovoltaic Cell PEDOT: PSS / P3HT: PCBM
}

\author{
T. Sahdane ${ }^{1}$, A. Laghrabli ${ }^{2}$, H. Bougharraf ${ }^{3}$, R. Benallal ${ }^{4}$, B. Azize ${ }^{5}$, B. Kabouchi ${ }^{6}$ \\ Molecular Spectronomy, Optics and Laser Instrumentation Team, Mohammed V University in Rabat, Faculty of \\ Sciences, Morocco $1,2,3,4,5,6$
}

\begin{abstract}
The mechanism and equivalent circuit model of organic photovoltaic cell were analyzed, and the simulation system of current-voltage (I-V) characteristics of organic photovoltaic cell was established by gpvdm software. Using numerical modeling we show that the increase in efficiency is caused by optical absorption in the pure polymer layer and hence efficient charge separation at the polymer bulk-heterojunction interface between the poly $(3,4$ ethylenedioxythiophene):poly(styrenesulfonate) (PEDOT:PSS) and poly(3hexylthiophene): phenyl- $\mathrm{C}_{61}$-butyric acid methyl ester (P3HT:PCBM) layer. The effect of internal series resistance and shunt resistance on its I-V characteristics, open circuit voltage and short-circuit current was quantitatively simulated.
\end{abstract}

Keywords: Organic photovoltaic cells, P3HT, PEDOT, open circuit voltage, short-circuit current

\section{INTRODUCTION}

A Photovoltaic effect of solar cells as a clean energy is the focus of current research, however, the organic photovoltaic cells have received much attention in recent years as they offer an environmentally friendly and low cost solution [1-4]. Traditional inorganic materials solar cell due to complex production processes, equipment, silicon material limited and the conversion efficiency reached the extreme and other reasons, its in-depth development has been greatly limited. In recent years, the research of conductive polymers has made it possible to develop low-cost organic polymer photovoltaic cells, which can improve the performance of solar cells, reduce the manufacturing cost and reduce the environmental impact of large-scale production [5]. The advantages of the organic compounds of a wide range of organic molecules easy to modify the chemical structure of the compound preparation of simple purification process is easy to be made of flexible devices, special shape devices and large area devices. Currently, the organic photovoltaic solar cell photoelectric conversion efficiency and inorganic Solar cells are still relatively low, so how to improve the conversion efficiency of organic photovoltaic devices is the focus of their research.

Organic solar cells and inorganic solar cells similar to the principle, are based on the semiconductor interface near the photovoltaic effect of the current inorganic solar cell theoretical research is more mature, and organic semiconductor photo-generated current generation process and theoretical description is still in development. The research on the I-V characteristics of the organic solar cell from the macroscopic aspect is helpful to master the photoelectric characteristic of the photovoltaic device.
The photocurrent generation and the carrier transport of the organic photovoltaic device can characterize its microstructure function, and its output characteristic can effectively reflect the organic solar cell. The structure design and material selection of organic photovoltaic cells have important significance for improving the photoelectric conversion efficiency of organic photovoltaic cells. The offset of band edges of the HOMO and LUMO levels will prove responsible for the improvement of all photovoltaic properties of the organic solar cells. Since a deep HOMO level is desirable for obtaining high open-circuit voltage $\left(\mathrm{V}_{\mathrm{OC}}\right)$ since maximum value of the $\mathrm{V}_{\mathrm{OC}}$ is determined by the energy difference between the HOMO (Highest occupied molecular orbital) level of the donor and LUMO (lowest unoccupied molecular orbital) level of the acceptor [6-8]. In this paper, the equivalent circuit model of the organic photovoltaic cell was studied, and the simulation was established by using gpvdm software. The structure layers are shown in Figure (1), and the energy level diagram of two-layer solar cells device has been given in Figure (2).

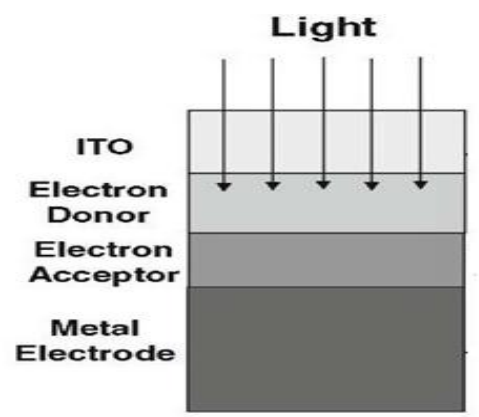

Fig.1. two-layer organic photovoltaic cell 
Vol. 5, Issue 10, October 2016

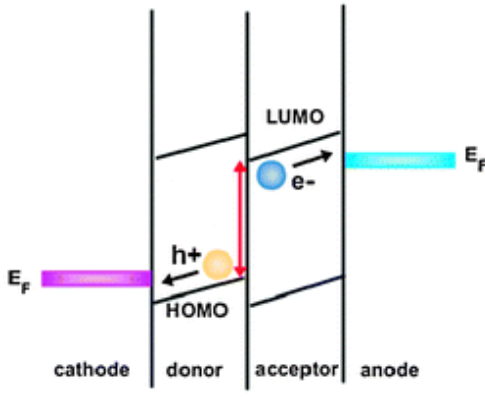

Fig.2. Energy level diagram of two-layer organic photovoltaic cell

\section{THEORETICAL METHODOLOGY}

The power conversion efficiency (PCE) is mainly determined by the short-circuit current density (Jsc) and the open circuit photovoltage $\left(\mathrm{V}_{\mathrm{oc}}\right)$ [9-10]. The PCE can be expressed by the following equation [11-12]:

$$
P C E=\frac{P_{\text {out }}}{P_{\text {in }}}=\frac{J_{\max } \cdot V_{\max }}{P_{\text {in }}}=\frac{F F \cdot V_{O C} \cdot J_{S C}}{P_{\text {in }}}
$$

Where, $\mathrm{P}_{\text {in }}$ is the incident power density, FF is the fill factor and $\mathrm{J}_{\mathrm{sc}}$ is the short circuit current.

For the short-circuit current density Jsc it is determined as [13]:

$$
J_{S C}=\int_{\lambda} \operatorname{LHE}(\lambda) \Phi_{\text {inject }} \eta_{\text {collect }} d \lambda
$$

Where $L H \mathrm{E}(\lambda)$ is the light harvesting efficiency, $\Phi_{\text {inject }}$ is the electron injection efficiency and $\eta_{\text {collect }}$ is the charge collection efficiency.

LHE can be expressed as [14]:

$$
L H E=1-10^{-f}
$$

Where $\mathrm{f}$ is the oscillator strength.

To analyze the relationship between $\mathrm{V}_{\text {oc }}$ (Open-circuit photovoltage) and the energy of LUMO ( $\left.\mathrm{E}_{\mathrm{LUMO}}\right)$ of the compounds based on electron injection from LUMO to the conduction band $\left(\mathrm{E}_{\mathrm{CB}}\right)$ of the semi-conductor [15]. Circuit diagram has been given in Figure (3).

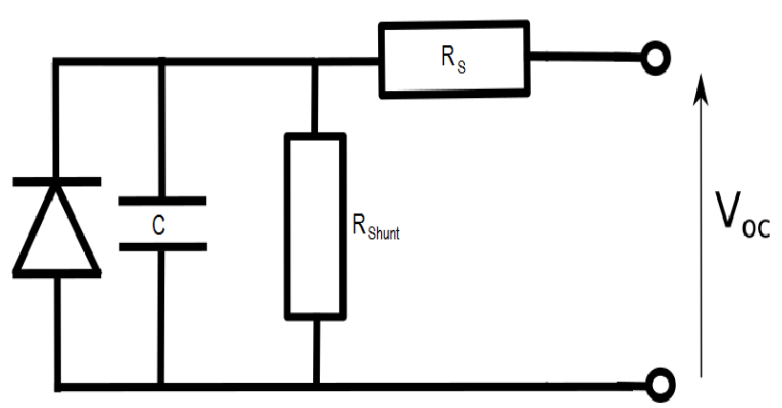

Fig.3. Equivalent circuit of organic solar cell

\section{RESULTS AND DISCUSSION}

In order to better, understand the reason for the increased efficiency of the bilayer devices, we using gpvdm capable of simulating both the electrical and optical properties of the bilayer structures. Materials used for the design and bandwidth values data of materials are given in Table (1).

Table 1. Layers of solar cells, optical material used for layers and bandwidth values

\begin{tabular}{|l|l|l|}
\hline Layer Name & Optical Material & $\begin{array}{l}\text { Band } \\
\text { Gap (m) }\end{array}$ \\
\hline ITO (anot) & ITO & $1.010^{-07}$ \\
\hline PEDOT:PSS & Generic_Organic & $1.010^{-07}$ \\
\hline P3HT:PCBM & Generic_Organic & $2.010^{-07}$ \\
\hline Al (katot) & Al & $1.010^{-07}$ \\
\hline
\end{tabular}

Figure (4) shows the effect of different $R_{S}$ on output characteristics at $R_{\text {shunt }}=100 \mathrm{~K} \Omega$. The series resistance $R_{S}$ of the organic photovoltaic cell is a composite resistance of the contact resistance and the organic thin layer resistance, so whether the electrode and the organic active layer of the battery are effective ohms Contact and organic active layer of the size of the body resistance, will directly change the size of R. From the simulation diagram shows that with the series resistance increases, the curve of the intersection with the vertical axis is changing, the current decreases, and the battery-filling factor FF also reduced while the conversion efficiency of the battery is reduced. At the same time, the intersection of the curve and the abscissa does not change during the course of $R_{S}$ change, indicating that the change of the series resistance has no effect on the open circuit voltage.

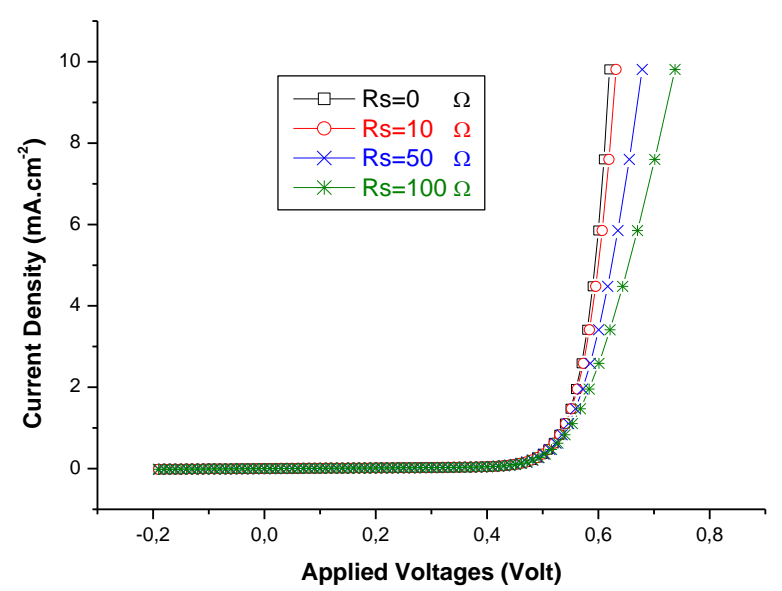

Fig.4. Influence of $\mathrm{R}_{\mathrm{S}}$ on $\mathrm{I}-\mathrm{V}$ of organic solar cell

Figure (5) shows the effect of different $\mathrm{R}$ shunt on output characteristics at $\mathrm{R}_{\mathrm{s}}=1.0 \Omega$. The shunt resistance $\mathrm{R}_{\text {Shunt }}$ must be higher to avoid current loss at the junction diminishing the photocurrent and hence the solar cell performance. It is well known that the shunt resistance of any photovoltaic cell should be large enough for higher output power and FF. It is observed that the smallest value 
of $\mathrm{R}$ Shunt causes PV cell current to fall more steeply indicating higher power loss and low FF.

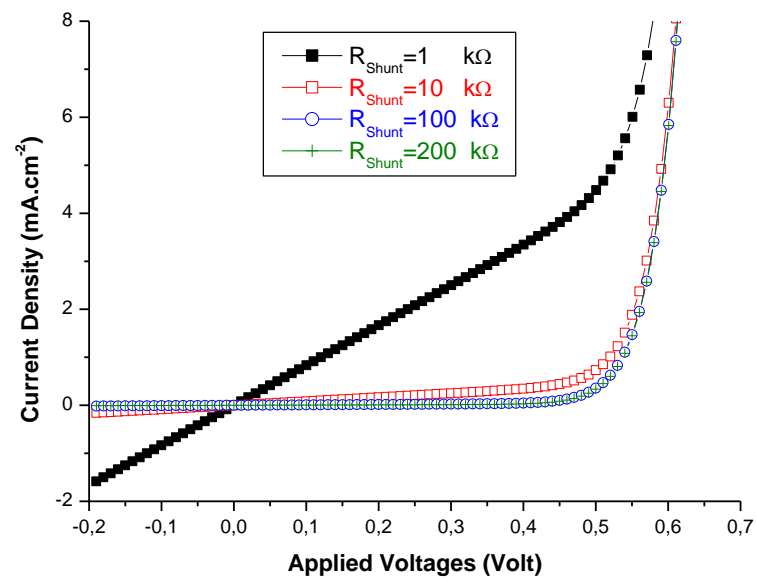

Fig.5. Influence of $\mathrm{R}_{\text {shunt }}$ on $\mathrm{I}-\mathrm{V}$ of organic solar cell

Photon density, energy variance of organic solar cell layers is given in Figure (6).

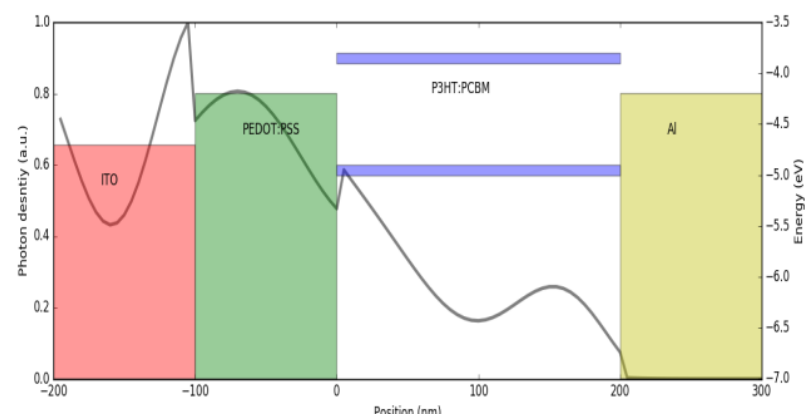

Fig.6. Photon density-location- energy variance of analyzed organic solar cell

Photon absorption, energy variance of organic solar cell layers is given in Figure (7).

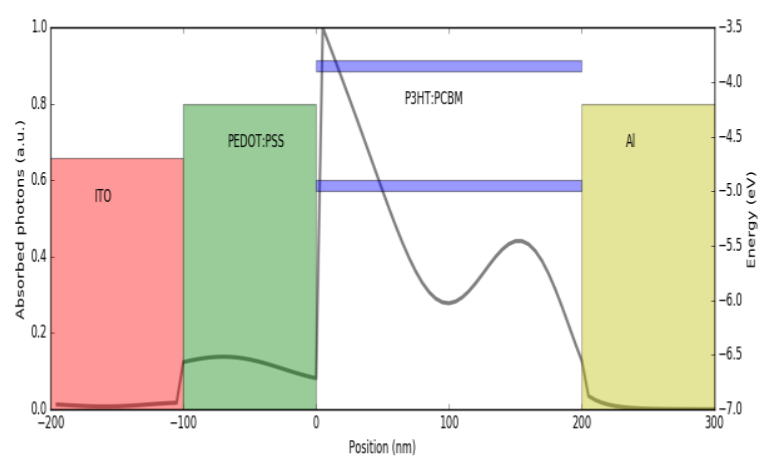

Fig.7. Photon absorption -location- energy variance of analyzed organic solar cell

The open-circuit voltage $\left(\mathrm{V}_{\mathrm{OC}}\right)$ is related to the $\mathrm{R}_{\text {shunt }}$, and has nothing to do with the $\mathrm{R}_{\mathrm{S}}$. On this basis, we have established a simulation for the relationship between the open-circuit voltage and the shunt resistance, as shown in Figure (8).

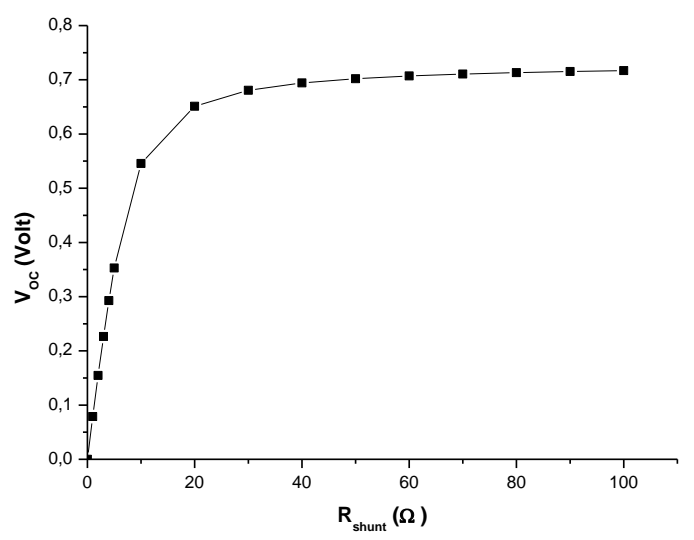

Fig.8. Influence of shunt resistance on open circuit voltage $\mathrm{V}_{\mathrm{OC}}$

The short circuit current is mainly affected by $\mathrm{R}_{\mathrm{S}}$, and the shunt resistance has little effect on the short-circuit current. The results shown in Figure (9), with the series resistance Increase, short-circuit current decreases (take the absolute value of short-circuit current).

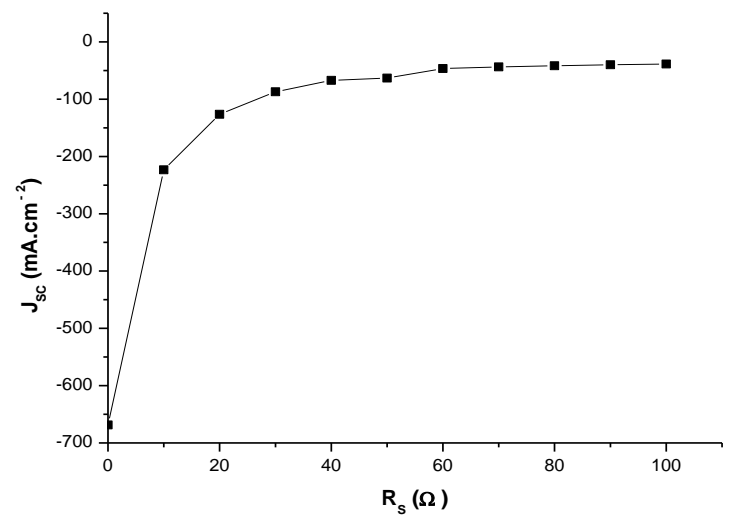

Fig.9. Influence of series resistance on Short circuit current

To examine if the change in $\mathrm{R}$ shunt could explain the increase in percent efficiency, a series of I-V curves were simulated with the calibrated model using different $\mathrm{R}_{\text {Shunt }}$ and the resulting device efficiency plotted. The results can be view in figure (10).

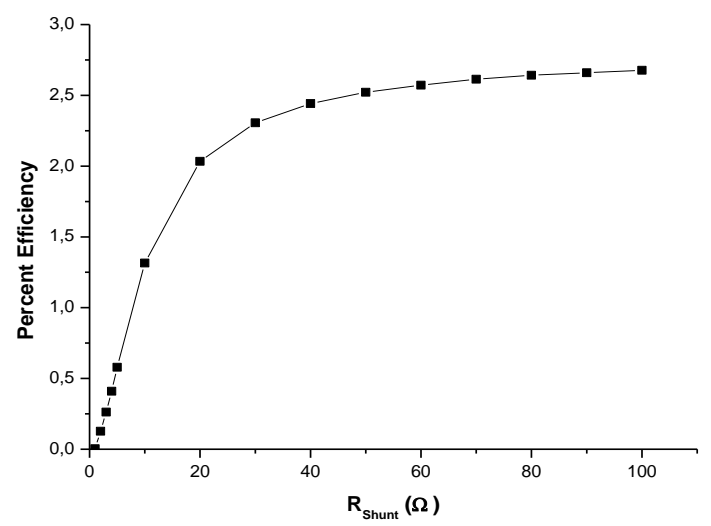

Fig.10. Influence of shunt resistance on percent efficiency 


\section{CONCLUSION}

In this paper, based on the analysis of the mechanism of organic battery, the equivalent circuit model of organic photovoltaic cell was studied. The simulation system was generated by gpvdm software. The output characteristic curve of organic photovoltaic cell was simulated. From the characteristic curve of organic battery, organic photovoltaic cell and The current-voltage characteristic curve of inorganic solar cells is similar, but the shortcircuit current of organic photovoltaic cells is much smaller than that of inorganic photovoltaic cells, which leads to the low photoelectric conversion efficiency of organic photovoltaic cells. After the series resistance and shunt resistance of organic photovoltaic cells to output characteristics The results show that the change of series resistance has no effect on the open-circuit voltage and the change of shunt resistance has little effect on the shortcircuit current. It is found that the decrease of series resistance and the increase of shunt resistance can make the filling the photoelectric conversion efficiency of the cell is also increased. The equivalent circuit model can describe the output characteristics of organic photovoltaic cells. The results show that reducing the series resistance of organic solar cells and increasing the shunt resistance are the key to improve the photoelectric conversion efficiency. The current research mainly focuses on device optimization and material selection.

\section{REFERENCES}

[1] G. Sliauzys, K. Arlauskas, V. Gulbinas, Photogeneration and recombination of charge carrier pairs and free charge carriers in polymer/fullerene bulk heterojunction films. Phys. Status Solidi A 209.7. 2012, 1302-1306

[2] H. Y. Chen , J. H. Hou , S. Q. Zhang , Y. Y. Liang , G. W. Yang , Y. Yang, L. P. Yu, Y. Wu, G. Li, Nat. Photonics 2009, 3 , 649 .

[3] N. Berube, V. Gosselin, J. Gaudreau, M. Cote, Designing Polymers for Photovoltaic Applications Using ab Initio Calculations. J. Phys. Chem.117, 2013, 7964-7972

[4] S. H. Park, A. Roy, S. Beaupré, S. Cho, N. Coates, J. S. Moon, D. Moses, M. Leclerc, K. Lee, A. J. Heeger, Nat. Photonics, 2009, 3, 297.

[5] H. S. Nalwa, Handbook of Organic Conductive Molecules and Polymer. 1997

[6] M. C. Scharber, D. Wuhlbacher, M. Koppe, P. Denk, C. Waldauf, A. J. Heeger, C. L. Brabec, Design Rules for Donors in BulkHeterojunction Solar Cells-Towards 10\% Energy-Conversion Efficiency. Adv. Mater., Vol. 18, 2006, Issue 6, pp. 789-794

[7] H. Zgou, S. Boussaidi, A. Zahlou, M. Bouachrine, M. Hamidi, Donor-Acceptor Organic Materials with low Band-gap for Photovoltaic Applications: a Theoretical Investigation. International Journal of Advanced Research in Computer Science and Software Engineering. 2014, 4(5). 10-19

[8] N. Belghiti, M. Bennani, M. Hamidi, S. M. Bouzzine, M. Bouachrine, New compounds based on anthracene for organic solar cells applications, Mater. Env. Sci., 2014, 5, 2191.

[9] B. Kippelen, J. L. Bredas, Organic photovoltaics, Energy Environ. Sci., 2009, 2, 251-261

[10] S. Ren, M. Bernardi, R. R. Lunt, V. Bulovic, J. C. Grossman, S. Gradecak, Toward Efficient Carbon Nanotube/P3HT Solar Cells: Active Layer Morphology, Electrical, and Optical Properties, Nano Lett. 2011, 11, 5316-5321

[11] M. R. Narayan, Review: dye sensitized solar cells based on natural photosensitizers. Renew. Sust. Energy. Rev. 2012, 16, 208-215
[12] M. G. Walter, A. B. Rudine, C. C. Wamser, Porphyrins and phthalocyanines in solar photovoltaic cells, J. Porphyrins Phthalocyanines; 2010, 14: 759-792

[13] Hua Guo, Daiqian Xie, Weitao Yang, Guosen Yan: A Festschrift from Theoretical Chemistry Accounts. 2015

[14] Z. L. Zhang, L. Y. Zou, A. M. Ren, Y. F. Liu, J. K. Feng, C. C. Sun, Dyes Pigm. 2013, 96, 349-363

[15] W. Sang-aroon, S. Saekow, V. Amornkitbamrung, J. Photochem. Photobiol. A. 2012, 236, 35-40 